\title{
THE ART THERAPY, AN AESTHETIC AND ARTISTIC EXPERIENCE TO SUPPORT THE INTEGRATION AND PREVENTION OF UNEASINESS
}

\begin{abstract}
Ferrara Lydia
Department of Pharmacy, University of Naples “Federico II,” via Domenico

Montesano, Naples, Italy

Flammia Aurora

ISFOM, Istituto Formazione Musicoterapia, corso Vittorio Emanuele corso Vittorio Emanuele, Naples, Italy
\end{abstract}

\begin{abstract}
Art therapy is a means of expression, a communication tool that represents the imaginary through the non-verbal. The present work is a proposal for a project to be carried out in Universities, in order to try and experiment with students the language of symbols, specifically the paint, draw, shape, dance, write, recite: activities in which all the senses are stimulated. Art therapy is an ideal instrument when, for students of all ages, in situations of crisis or at the margins of the social context, anxiety and stress cause somatization disorder, when you cannot reproduce existential dramas or tragic events, when verbal expression is impossible or deficit for various causes so the bodily and psychological integrity is at risk or compromised.
\end{abstract}

Keywords: Art therapy, support, expressive capacities, uneasiness

\section{Introduction}

Art therapy is the set of treatments using main tool the artistic expression in order to promote health and promote healing, and is proposed as a technique of multiple application contexts, such as therapy, rehabilitation and education/prevention (Improta, 2005). It has been a valuable tool in support of psychiatric care of people with severe mental disorders, such as psychotic and autistic (therapeutic area). The latter subjects were able to express themselves better with the body or with gestures, materials modelling, dancing, or representing in drawings their fears, rather than through words; the use of artistic expression, could help 
them to overcome the serious difficulties in communication, which are typical of people suffering from these disorders.

These results led to extend the use of these techniques also to patients less serious, with mood disorders and anxiety disorders, in which there is, thanks to the use of art therapy, an increase of self-esteem, a consolidation of the ego and the improvement of social skills (Pasanisi, 2001). The success achieved in therapy led to extend the use of art therapy in the rehabilitation of patients with neurological damage and physical disability, but no real mental illness. Creative activities help these people reduce the denial of disability, to develop greater personal autonomy and social relations (Warren, 1995). As for the area of education, art therapy is increasingly being used by common people, not carriers of the specific hardships, as a form of education being addressed with sensitivity, creativity, to selfawareness and to self-acceptance. The path of art therapy to adults of all ages, require no special skills or artistic talents, but facilitate creative expression by offering opportunities to meet yourself and others, useful to discuss personal issues to deal with times of change, discover new personal resources.

For children and adolescents, the paths of art therapy, assure listening and opening, lack of judgment and maximum encouragement to individual creativity, resulting valid and effective tools in schools (from kindergarten to high school) and in recreational and educational such as youth centres of aggregation or communities for children. Just for the younger ones, projects could be promoted aimed at supporting those who are in conditions of social disadvantage, uneasiness with psychological/behavioural disabilities, foreigners, involving them in the release of emotions and experiences, to know and discover oneself in a playful and creative way.

Many are situations in which both adults and children are in moments of 'crisis', and feel the need to readdress the balance with themselves and with the outside world (bereavement, separation, failure in school or work, etc.): art therapy can help them express and process their emotions to deal with their conflicts, and regain self-confidence. Among the art forms, primarily used in art therapy you can mention all graphic arts, from drawing to writing; the dance; the music; theatre and cinematography. Creativity is at the centre of human development: it allows, throughout life, to recover confidence in creative and transformative capacity

The setting of art therapy as a therapeutic space delimited, protected and assured that holds, supports and facilitates such holding environment. It must be adequate, comfortable, ordered and stimulating to allow the memory of archaic processes of focus. In it are, in effect the normal social rules, the atmosphere is serene, and everyone feels accepted and not judged. The 
physical relationship with the materials present in the patient wakes up, setting the experiences of contact and pre-verbal communication; stimulates the symbolic expression of the contents of the unconscious; and allows the creative act of expressing all the transformative potential. In this space, the therapeutic process takes place within the triadic relation between subject/patient, therapist, expressive (even potentially): none of the three leaders of the report may be missing or do without the other, and each receives from the other two thicknesses, which results in a more complex dynamic transferal-controtransferale. Each material used implies different messages, depending on the tactile quality, control possibilities that offers the degree of muscular involvement required, and can be chosen for that particular subject/patient following proper observation, given the defence, the level of object relations, I outline. Even the therapist proposes a material rather than another, depending on the psychological demand of the moment: support, comfort, challenge, reflection. What is being created (not the finished product, but the vicissitudes of his emergence) is never just a translation abstract thinking or representation, but is an unconscious and an incarnate expression of a lived; not a pure transcription of a lived in concrete, but a reworking of living and reactivate a process that may have been inappropriate, or distorted, or blocked. What is created, depending thus on the time and the report can perform several functions (complementary, integrative, reparative): transitional function, a bridge between the internal world and external reality, between Self and other by Self, between patient and therapist (for example, in times preceding the separation, incorporating elements of the patient and the therapist); or narcissistic function, which is the subject of Self reflecting and supporting the patient's Self. The means of expression of the creative process become a bridge between the various parts of the self, between the inner world and the outer world, between patient and therapist, between himself and the other members of the Group; become a vehicle through which they can communicate, and at the same time you can hide what cannot, or cannot yet be expressed. Processing work can then be carried on a plan of greater knowledge, for example through verbal interpretations; or remain on a more symbolic level with metaphorical interpretations and verbal associations.

However, to date, there are few data and clinical studies conducted in Italy, contrary to what is found in the countries of Europe and North America, where the art therapy is recognized and practiced for decades to the psychological support of patients. In Italy, has not enjoyed wide acclaim that made it possible to develop and share a theoretical system that scientifically right: there are indeed tasks, techniques, shared objectives and commonly accepted, nor a training or professional ethics. Despite this, the efficacy demonstrated by experimental evidence reported in the literature, has 
launched the basis for the use of art therapy in private structures in our country. Art therapy is used in various contexts, from therapy to rehab until the educational contexts. Although there is some scientific decoding tool of art therapy, such as the Polisegnico model (De Gregorio, 2000), a fix yet found is to quantify the benefits produced by the art therapy, whereas for the scientific community is valid if treatment is quantifiable and repeatable.

The proposal of an art therapy-oriented laboratory in University, stems from a fundamental assumption: non-verbal communication is of considerable importance for the evocative and relational potential of each person. It represents an essential vehicle to intervene also on students unease, in particular regarding: closing behaviours, difficulty of integration and communication with peers and teachers, specific issues related to disability, attitudes of burn out, desire to surrender.

\section{Method}

This method dynamically addresses the world of sound, image, movement, appropriately and scientist, using the most diverse sensory and communicative registers. It places students in the face of various languages (verbal, corporeal, mimic-gestural, sound, etc.) and offers the opportunity to experience them directly in order to enrich the training offer, stimulate creativity, express emotions and feelings suppressed (or where it is difficult to speak); identifying and addressing conflicts and emotional blocks; improving the knowledge and the relationship with your body. This method increase self-esteem and the perception of effectiveness; assert yourself and your identity-individuality; develop new strategies of behaviour; increase your interpersonal skills and communication skills; prevent the phenomenon of failure and work on specific cognitive and communicative goals, motivating participation in University life and resizing the difficulties linked to the preparation of examinations and inadequate compared to the demands of the teachers. This proposal aims at enhancing moments and spaces that welcome and support students in a location in which to search within themselves what can be and represent, through non-verbal languages. The use of art materials (colours, chalk, paper,...), voice, body and art-therapeutic techniques, are meant to develop creativity and the ability to represent, to fill in the world, and part of it.

Making art, in the sense of engaging in new and creative activity, also promotes the activation of the right hemisphere of the brain, which governs precisely the creative activity of the imagination, intuition, communication and bodily signals (analogical thinking). The lateral thinking, in fact, whose evolution is encouraged by the activation of the right hemisphere (De Bono, 2000), makes it possible to identify criteria and dominant ideas that usually polarize perception of a problem, then look for 
new ways to count and operate in reality, and therefore to construct more flexible the rigid restraint of the rational logical thinking and stimulate the growth of creativity.

The project will consist of the succeeding stages: the first, information and communication to students of the Institute through a notice on the bulletin boards or information through media, television media and journalism; the selection phase that can be accessed by internal and external students, unemployed youth and adults and unemployed and job seekers, Italians and foreigners, men and women, family groups, handicapped. The selection will be curated by a Special Commission who will deal with deepening and professionalization to the needs of so-called at-risk subjects (learning disability) getting a mapping of strong or weak sides of the participants.

The terminal phase is that of laboratories, divided into theoretical moments-cognitive and practical operational times. During the workshops will offer an overview of the history, training and read mode of the main themes, in particular the emphasis on the relationship between the characteristics and the employment of individual artistic productions. The activities will lead to the acquisition of theoretical and practical knowledge of the techniques and instruments relating to expressive communication. Cultural and educational content presented to participants to provide basic knowledge of materials, shape, composition, artistic techniques and allow everyone to freely express their artistic impulses. The workshops will feature both amateur and specialization approaches (particularly versatile individuals). Laboratory appointments will be interspersed with preparatory measures of Arts Education, held by the master, encouraging careful reading of creative dynamic that will demonstrate.

The central methodology of the sessions is the inductive-deductive, to solicit participants to capture affected, under the guidance of art therapist and art masters since then revealed aspects emerged about the cognitive and emotional arena, creative solutions and outline a possible shared operating outlet. The focus of the observation will give priority to the observation through role-play techniques. In this process, the content is not the starting point, but the arrival, spilling what generally is the learning-teaching process used in university classrooms. The methodological approach, transversal and avant-garde, presupposes the awareness of necessity, at an intermediate stage, a bracketing: this essential adjustment possibilities of the project will come from a practice thought and organized such a theory and a method less weak.

It's also important to take account of the increasingly significant issue, the increase of non-EU students, as well as that relating to the inclusion of persons with disabilities and the need for targeted interventions 
that allow both integration with able-bodied individuals who develop residual capacities. The challenge is to create contexts, that help students to gain knowledge, skills, confidence and motivation to compete with more resources with the University world and later that of work.

The drawing and paintinglaboratory is used to acquire or enhance the ability to contact the emotions and represent them in a fantastic dimension through shape and colour. In addition, requiring the activation of visual-motor coordination and the ability to fine and precise movements, involves also a strictly motor benefit. The drawing has three meanings: a playful meaning (to create) a narrative meaning (to tell oneself), and a cognitive meaning (for asking and answering of questions). But especially, the drawing has a projective value: it allows to explaining one's conflicts and anxieties that, assuming concreteness and becoming something external to it, can finally be dealt with less anxiety-provoking. Any type of drawing contains obviously projective aspects, for the way in which space is used (in this case the sheet), stroke type, and colours. It can also be used as a tool for analysis of group dynamics and the way in which each individual interacts. Proposing, for example, a drawing of the group - where both space (the sheet), tools (colours, pencils, etc.), and the theme will be shared - are evident power dynamics and how that group processes for the resolution of conflicts, as well as the way in which each member relates to others.

As for the painting, can be used all the tools and all the painting techniques: markers, tempera, watercolours, finger paints, collage, etc. Each choice of a certain tool has a symbolic value: while, for example, markers, easy to use and with a sudden sharp and defined, give safety, the paints and still more, the finger-paints get dirty and require a greater involvement, and in fact are not usually used by people with obsessive-compulsive traits. The collage, which requires less creative effort because it is just to assemble, it is usually chosen by people who feel somehow threatened by a creative freedom too. The choice, however, to use more tools together, is a sign of great flexibility and is very useful in the development of lateral thinking, which goes beyond the classical patterns. The writing laboratory that in art therapy takes various names (writing therapy, poetry therapy, bibliotherapy, etc.) depending on the technique mostly used, implies the intentional use of writing as a therapeutic tool. In fact, it is used in different ways, to choose and adapt to the characteristics of persons and therapeutic goals, but it is possible to distinguish an active mode and a passive mode. In active mode, the subjects are invited to compose poetry or literary excerpts, free or starting from a subject or keywords indicated by the therapist. In this case, writing has principally an expressive function and represents an important opportunity to get more into greater contact with themselves, achieve greater self-awareness and new, and often unexpected insights. Passive mode, on the 
other hand, requires reading, according to a personal interpretation of existing tracks. In this case the function is evocative, and mainly relies on of projection and identification mechanisms. The use of writing is particularly suitable with very rational people and they usually find it difficult to recognize and express their emotions.

With regard to the dance laboratory different variants have been developed (bio-dance, dance therapy, dance-movement therapy), which share the use of movement, with or without music, as the main therapeutic tool. Muscle tension and postural and movement mode (use of space, timing, rhythm, etc.), reflect the tensions and psychological ways, so work to take awareness and dissolve such physical tension involves contact and resolve emotional and psychological blocks.Just because body language replaces the verbal (Colombo, 2006), the main goal is to get in touch with own body and listen to the emotions that dwell there. The benefits of the use of movement and dance are at several levels: to a physical level allows extending the motor repertoire and improve coordination and muscle tone; at the psychological level, it acts in the way of self expression and adapting to reality, at a social level, finally, works on the way to interact with the group and then on the communicative- relational skills.

As for the music laboratory, we speak mainly of Music Therapy. Music is a very powerful tool, especially for its evocative value and regressive. Make or listen to music, in fact, activates hypothalamus of the brain areas related to the most ancient survival mechanisms, while the rhythm returns to contact with the maternal heart rhythm in uterine phase. The music introduces the person in an atmosphere where the relationship with psychological aspects of self-consciousness is weakened by allowing you to get in touch with the deepest parts of the psyche. In addition, facilitates both physical and mental relaxation and improves the physiological functions (breathing, heartbeat and blood pressure). Also, it can be used in therapy in active form, producing music with different instruments (usually drums), and passive, leaving soothed by notes of songs chosen by the therapist according to therapeutic purposes. The aim is to help the individual to explore the emotional experiences derived from contact with music and re-elaborating his images and memories erased.

The therapeutic effects of the laboratory of Theater dates back to the times of Aristotle and ancient Greece: the beneficial effects and the catharsis that stemmed from a tragedy, however, were passive, while theatrical techniques in art therapy (psychodrama, theatre-drama therapy, playback theatre), are used actively and therapy purposes. Dramatize and translate words into action allows a more direct access to the internal contents of the subject, which can re-live process and past events, and resolve conflicts reenacting them self, explore their own ghosts making concrete and external 
rendering unto itself, and therefore more accessible and more easily modified, or even experiment in new situations, thus increasing own skills and self-knowledge. In addition to the representation of realty and psychodrama, very good can be theatrical plays, usually used as a heating of the group, as to create the necessary atmosphere for a free and spontaneous self- expression, and the use of masks, which can be built and painted by the students themselves, and the interpretation of monologues.

In the laboratory of cinematography are experiencing the beneficial effects of watching a movie: as in dreams, images have a character of reality while not intruding into reality; they meet the imaginary needs and more intimate drives, allowing the hallucinatory satisfaction, and are subjected to the same intrapsychic processes: displacement, projection, forgetfulness, oblivion, etc. (Musatti 1960). The session also presents film a whole host of features that promote involvement so strong, as the darkness, high volume, the relaxed position, passivity. Watching a movie cancels, at least temporarily, surrounding reality by activating the mechanisms of identification, so a deficiency or an internal need are mitigated by identifying precisely, emotions and feelings of the characters in the movie; projection, so addressing internal conflicts or more unpleasant aspects of itself as objective worked on the characters in the movie. When it is possible, the awareness of these processes can be a very important moment for personal growth. Even the cinematography is used in art therapy is in the passive form, and therefore closer to cathartic effects mentioned by Aristotle, both in active form, involving the group in the writing the screenplay and the production movie itself, in which, of course, will be the protagonists.

The arts can be used synergistically. For example, you can invite participants to make a paint taking inspiration from music, or ask to play or dance a poetic or musical piece. Use different sensory and communicative registers, or switch from one to another can be very useful for promoting flexibility and fluidity and deal with the same themes from a different perspective.

\section{Objectives}

In the current society, where we are subjected to a hectic lifestyle and to an excess of stimulation, it gives less importance and space for imagination and creativity - penalizing the real knowledge of oneself and of one's emotions. The purpose of art therapy is regaining possession of space and time, boosting the resources and the autoregenerative potential, express their emotions, whatever they are, deal with the deeper aspects, and experiment in different skills, to promote self-awareness and maintain or regain the psychological well-being, not only through the treatment of the 
disease but also through the transformation, the evolution and inherent growth of every individual.

In this project we wanted to emphasize the importance of art therapy such as un-conventional therapy, used as a treatment for certain pathological conditions, often chronic. Through a speech and non-verbal support, the creative process put in place in making-art produces wealth and improves the academic performance and the quality of life, becoming, a process of education, where educate is for educere, or take out, to bring out the awareness and greater self-knowledge through the practice of expression, observation and comparison (Naccari, 2001). Educating with the use of artistic techniques to creatively contribute to amend or contain personality traits (obsessive, conformity, acquiescence, negativity) that sometimes might evolve into some diseases. Art can motivate a lot, since it allows physically and symbolically to recapture natural law to produce a footprint and engage in creative activity, leads to a series of physical, emotional and intellectual changes that produce organic and psychological changes that promote healing processes. (Warren, 1995). Each pathway involves the participation both individually and in groups in one or more laboratory, to facilitate the production/expression of each participant or the interaction between everyone. The presence of the group in fact performs multiple functions: first of all, it creates an atmosphere of spontaneity and the feeling of containment required so each member can express themselves freely; it also offers an important opportunity for comparison and growth discussing the experiences of individual members; in addition, allows to the subject to realize that he is not the unique in a difficult situation, but he is, even in the specificity of personal experiences, in a situation common to other and from other partecipated. It is easier to talk about a drawing, a poem, a song, a movie or any other artistic product, that talked about oneself. Therefore, is effective in the treatment of psychological, social or physical discomfort, and prevent discomfort. The value of the work produced is not in artistic quality, but in its meaning: create with their own hands something that makes sense to the person means to regain the power to act and then to choose; to find themselves testing through the sign, the sound , movement, etc., and therefore return to be actors and not mere spectators of their own lives.

In fact, the overriding objective of the work, entrusted to experts, is to accompany students in activities oriented to good communication and integration in groups; to awareness of the expressive gesture (the translation of emotions through a corresponding objectivity); to appropriation of imitative, production, improvisation, capacities, listening self and other; the use of instrumental means and the desire to live more consciously his own person/identity. 
In expressive / creative laboratories required by an expert of the institute helped by an equippe of masters, activities will take place to experience the visual arts - sculpture, painting, ceramics - musical and gestural and will be able to enhance their expressive abilities, will also promote the paths of non-verbal communication useful to identify / address the needs / problems of the students, supporting them in the path, recovering elements for decoding of their behaviors.

The art therapist does not evaluate or judge, but facilitates and enhances attempts to tidy up that people experience with different artistic techniques, in absolute autonomy of expression. He is a professional who does not give solutions, a facilitator who accompanies the person to experience a way out through the expression. The creative process, regardless of the outcome, is not only about the treatment, but prevention against potential neurosis, psychosis, phobias, obsessions, prevention for healthy individuals because it relieves stress conditions and existential issues.

Making art (and not relate to an artistic product) in expressive/creative laboratories can become time to care and treatment, under the proficient guidance of art therapist, joined the art master, who must know how to use the best tools, adapting gradually to people and situations. The master, in the single laboratory, must ensure that the student can selfcorrect limiting direct interventions on him and giving him full liberty. It also organizes meetings and/or final exhibitions of discussions where verbalizing implemented processes and be rewarded.

The first meetings with University students are recommended prior to the start of the course to achieve a satisfactory degree of familiarisation within the group. Beyond master the art therapist must also be present, and he must observe and have moderator-mediator function. It is also essential that the master in the first person is concerned in the preparation, discovery, tuning, recovery, location of the tools required.

\section{Results}

Art therapy is the method that reduces the physical issues and improves interpersonal skills and socialization of the individual suffering from social discomfort. What is important is mainly the creative process in itself: the express themselves, create, rather than the final artistic product.

Acquisitions, expressive skills, behavioral, emotional, experience, interests and needs of recipients will be monitored and recorded in special observation sheets, prepared for each meeting by the supervisor of the work. This material will represent a final reading of the path, in addition to the questionnaire distributed to students in output of laboratories, on the expectations, performed, levels of satisfaction and operational and technical 
aspects, during the laboratories. The items of documentary material, designed and prepared by the supervisor, will take account of the specific factors for a psycho-dynamic reading of behaviour expressive and communicative attitudes of the individual in relation to the group. The work will be supervised by the supervisor/art therapist in periodic meetings with the conductors/master of laboratories and returned in the form of documentary material. The work of the supervisor provides instruments for monitoring: periodic discussion about laboratories; observation and assessment of technical details of the work; reflections on the operations and the participation by the instruments used: questionnaires, cards, musical instruments-scenic, paintings and scenic used, video recordings; roleplaying/simulate where in the action refers to solutions and strategies of intervention.

You can also include the opening of a one-stop consultancy, in the days and hours specified in the program attached to the project. The specialists will provide assistance to those students who, inside and outside, living conditions of discomfort and disorientation social and/or academic, intervening in everyday life, in prevention to reduce stress, or in those situations where there is no need to get a good balance, in order to increase the level of general welfare (especially in periods when you are under examination).

The laboratory of art therapy is a large, bright, and full of stimuli. There is everything: paper, pencils, colors, patterns, fabrics, wool, wood, flour, towels, puppets, installations, musical instruments. You can also find an empty space, free from stimuli to fill as you wish. The work in workshops is experienced as a playful and funny that accompanies the student in one of the most fascinating journeys of humankind: the self-discovery. For anxiety and stress cause an emotional burden that can result in the effects: asthenia, headaches, sleep disturbances, gastrointestinal, respiratory and sexual (Tonini, 1997) if does not find adequate expression channels. The arttherapeutic approach gets, therefore, two important results: provide immediate emotional relief channel and allow a loosening of defenses that do not process the problematic experiences.

\section{Conclusions}

Our industrial and technologically advanced society has operated a clear separation between art and life. Consequently, the art is defined in terms of products that can be discussed or subject of criticism and evaluation, often more for their economic value than for the aesthetic or spiritual contribution for whole society. Over the centuries, developed the idea that artistic creation complete only to a narrow circle of individuals specifically equipped. In this way, you are denied the natural rights: the right 
to produce their own unique creative mark, a mark that no one else could create. Art therapy presented here aims to improve the quality of University life, because, through the creation, the student will be able to get in touch with their inner life and a better understanding of certain aspects of himself that will help you relate to others and in their performance. Through artistic expression and, with the contribution of technically trained experts and empathically present, he will receive the right indications, a greater courage and enthusiasm, to arrive with his own time, in small steps to give vent to impulses such as aggressiveness, anger, frustration, fear, suffering, shrugging off the negative emotion to project it, contingent on the paper, on canvas, on artistic support.

Psycho-physical deficiency can be realistically compensated, not eliminated, with deceptively designed on concrete conditions and projected toward possible, feasible size and livable with dignity. Students no longer feel trapped by a reality, contingent, unhappy. And the healthy emotional detachment allows them to take distance from the negative emotions and to look, from the outside, as observers, to regain a state of well-being, balance, and a more authentic contact towards awareness. The limit can thus become a resource.

\section{References:}

Colombo, C., (2006). Roots and forms of Dance Therapy, Milano: Saggi.

De Bono, E., (2001). Lateral Thinking, Milano: Rizzoli.

De Gregorio, A., (2000). The Polisegnic Model, inArt Therapy: the theoretical foundations, Torino: Tirrenia stampatori.

Fata, A., (2003). Therapy to 35mm, http://www.dica33.it

Kramer, E., (1971). Art as therapy with children,New York: Schocken Books

Improta, A., (2005). Art Therapy - The art of curing, Firenze: PsicoLAB.

Musatti, C., (1960). Cinema and Psychoanalysis, in Psicoanalisi e vita contemporanea, Torino: Boringhieri.

Naccari, A.G.A., (2001). Adolescence and dancemovementtherapy, the processes of DMT as educational opportunities, in Use in the art to not be on the sidelines, art therapy and good educational relationship, Proceedings of the National Conference sull'ArteTerapia in the School, Carpi 7 - 8 September, Ediz. Magi.http://www.apid.it/pubblicazioni.htm

Naumburg, M., (1966). Dynamically oriented art therapy: its principles and practices, New York: Grune \& Stratton.

Pasanisi,R.(2001). A new school of psychotherapy in Italy: the Art Therapy , in“Ecomind”,7/X/2000,www.ecomind.it/Sezioni/Articoli/Articoli html 
Tonini, G., Tamino, A., Bellotta, A., Bianchi, A., \& Notarangelo, N., (1997). Terapia dei trapianti e angosce quotidiane, speech at the XVI Congresso Nazionale S.I.M.P., Panna.

Warren, B., (1995). Art Therapy in education and rehabilitation, Trento: Erickson Edizioni. 